\title{
Desenvolvimento de uma webquest no contexto de uma abordagem interdisciplinar
}

Márcia Cristina dos Santos Ribacionka

Mauro Sérgio Teixeira de Araújo

Rômulo Pereira Nascimento

\section{Resumo}

Este trabalho tem como objetivos propor alternativas para o trabalho pedagógico na sala de informática, ampliando as possibilidades de sua utilização pelo professor de Matemática e a realização de uma atividade interdisciplinar, envolvendo questões adequadas para a faixa etária dos alunos da educação básica. Para isto, foram realizadas atividades baseadas no uso de algumas ferramentas da área de Tecnologia da Informação e Comunicação, com ênfase na WEBQUEST, sendo o trabalho realizado com grupos de alunos e professores do Ciclo II do Ensino Fundamental da Escola Estadual Gabriela Mistral, uma escola de Tempo Integral da capital do Estado de São Paulo. Os resultados obtidos mostram que a proposta trouxe significativos avanços nas interações professor-aluno e aluno-aluno, proporcionando maior facilidade de aprendizagem aos alunos e sinalizando caminhos para que o professor de Matemática possa realizar atividades na sala de informática, tendo como ênfase uma abordagem interdisciplinar dos conteúdos.

Palavras-chave: Tecnologia da Informação e Comunicação; webquest; interdisciplinaridade; metodologia de ensino.

\section{Abstract}

This work has as objects to propose alternatives to the pedagogical activities developed in the information technology classroom, extending the possibilities of use by Mathematic teachers and the realization of interdisciplinary activity, involving right questions to the student's age group of the basic education. So these, was realized activities based on Communication and Information Technology tools, emphasizing the WEBQUEST, developing the actions with groups of students and teachers of the Second Cycle of Basic Education in the Gabriela Mistral Public School, an integer time school of São Paulo. The results obtained show that the proposal gives significant advances in the student-student and student-teacher relations, generating facilities to the 
students learning and pointing ways to the Mathematic teacher realize activities in the information technology classroom, having emphasis in interdisciplinary approach of contents.

Keywords: Communication and Information Technology; webquest; interdisciplinary approach; teaching Methodology.

\section{Introdução}

O foco central deste trabalho é a apresentação de uma abordagem interdisciplinar da Matemática utilizando a sala de informática, espaço normalmente pouco explorado na maioria das escolas públicas da rede estadual de São Paulo e, neste sentido, procuramos desenvolver com os alunos uma Webquest, visando atingir diferentes objetivos educacionais. A Webquest pode ser considerada como uma metodologia de ensino em que utilizamos as páginas da Web para realizamos uma pesquisa orientada.

A atividade proposta foi realizada com alunos do Ciclo II do Ensino Fundamental da Escola Estadual Gabriela Mistral, uma escola de Tempo Integral situada no bairro Parque Edu Chaves da Capital do Estado de São Paulo. Esta escola é caracterizada por estar situada na periferia da cidade, tendo como parte de sua infra-estrutura uma sala de informática com onze computadores, todos conectados à rede de comunicação internet.

\section{A escola de tempo integral (ETI)}

Em São Paulo a Escola de Tempo Integral (ETI) foi planejada para ser implantada em 500 escolas selecionadas e pertencentes à Rede Pública Estadual, onde a presença do poder público se mostra muito importante, assim como para a maioria das escolas pertencentes a projetos desta natureza, auxiliando significativamente a população de muitas comunidades carentes.

Na Resolução SE no 89 de 09/12/2005, que dispõe sobre a Escola de Tempo Integral (ETI), temos no artigo 2 o os objetivos da ETI, que são:

I - promover a permanência do educando na escola, assistindo-o integralmente em suas necessidades básicas e educacionais, reforçando o aproveitamento escolar, a auto estima e o sentimento de pertencimento;

II - intensificar as oportunidades de socialização na escola;

III - proporcionar aos alunos alternativas de ação no campo social, cultural, esportivo e tecnológico; 
IV - incentivar a participação da comunidade por meio do engajamento no processo educacional implementando a construção da cidadania;

V - adequar as atividades educacionais à realidade de cada região, desenvolvendo o espírito empreendedor

No artigo 5o da mesma resolução encontramos ainda esclarecimentos sobre os componentes curriculares, estabelecendo parâmetros e fundamentos para as disciplinas diferenciadas, além do currículo básico, ou seja:

I - orientação de estudos;

II - atividades Artísticas e Culturais;

III - atividades Desportivas;

IV - atividades de Integração Social;

V - atividades de Enriquecimento Curricular.

Podemos atentar para o fato de que todas as disciplinas são colocadas como atividades, de modo que um dos objetos traçados é trabalhar com o aluno de forma a diversificar a aula, fazendo com que elas sejam diferentes daquelas apresentadas no currículo básico, com propostas de trabalho diferenciadas, evitando ou minimizando quando possível o uso de giz e lousa. Para isto, devemos explorar e criar outros ambientes educacionais, como bibliotecas, salas de leitura, sala de informática, de música, de experiências matemáticas, entre outras. Também devem ser utilizados espaços como o pátio e a quadra da escola, as ruas próximas, a feira livre, supermercados, bem como outros espaços que o professor puder fazer uso para incentivar e motivar a permanência do aluno por tanto tempo, sem que ele se sinta entediado. Assim, esperase que o aluno possa ampliar seus conhecimentos, sentir-se participante de suas realizações e ser capaz de obter uma formação integral, que o capacite para o exercício de sua cidadania.

Dentro deste contexto, trabalhar com a WebQuest pode promover outros aspectos além de conhecimento e integração, uma vez que podemos através dela abordar diferentes temas relacionados à diversas disciplinas, propiciando a tão almeja interdisciplinaridade da Matemática com as demais disciplinas da grade curricular.

Os meios tecnológicos despertam grande interesse nos alunos, ainda mais em uma região onde o acesso a tal tecnologia só é possível para a grande maioria dos alunos através da Escola. 


\section{A escolha do tema}

Entre os objetivos do trabalho podemos destacar o desenvolvimento e a utilização de uma metodologia de ensino de Matemática que permitisse sair do tradicionalismo reinante na escola e, assim, propiciar aos alunos condições para que pudessem relacionar uma atividade lúdica com alguns aspectos da Ciência e que normalmente estão presentes em seu mundo vivencial. Neste sentido, foi selecionado o tema "Pipas: Geometria e Lazer", pois através do ato de empinar pipas os alunos poderiam conhecer os conceitos físicos básicos que permitem às pipas voar e permanecer no alto, incluindo elementos como a sua forma, o que remete diretamente à Geometria.

Assim, trabalhando com um tema próximo ao cotidiano dos alunos, acreditamos ser possível estimular o envolvimento dos mesmos nas atividades propostas, atraindo a sua atenção e interesse. Dessa forma, acreditamos estar contribuindo para modificar o panorama educacional da escola onde o projeto foi realizado, valorizando por meio da estratégia empregda o fato que cada estudante tem seu modo próprio de aprender, apresentando um determinado nível de motivação e interesse pelas diferentes disciplinas. Assim agindo, procuramos também considerar as experiências de vida dos estudantes, que segundo Laburú (2003) devem ser consideradas. Entretanto, torna-se claro que quando utilizamos apenas uma única estratégia de ensino fica mais difícil para os professores terem condições de considerar e atender a individualidade dos alunos, pois estes apresentam diferentes respostas frente à diferentes situações de aprendizagem, conforme destaca Laburú e colaboradores (2003, p. 252):

Pode-se afirmar que todo ensino, como atividade humana é intercultural, devido às múltiplas identidades microculturais de todos os estudantes e, por essa razão, os indivíduos reagem e são afetados diferentemente pelas ações dos professores.

Assim, quando consideramos a individualidade de cada aluno, a aprendizagem se torna possível na medida em que seus conhecimentos prévios sejam o ponto de partida do processo. Assim, analisando o ensino baseado em livros didáticos, tende-se a abordar os conceitos como concepções prontas, impossibilitando a ocorrência de discussões críticas de modo que os alunos se vêem forçados a abandonarem suas idéias acerca do mundo, decorando o que os livros trazem, pois os professores impõem ao aluno a condição de ouvinte, relevando a sua experiência de vida. Na proposta de trabalho aqui descrita procuramos superar estas barreiras e avançar, ainda que minimamente, em direção a uma educação mais envolvente, crítica e participativa. 


\section{A interdisciplinaridade como base da metodologia de ensino}

Podemos afirmar que o mundo em que vivemos é interdisciplinar, pois devemos avaliar as diferentes situações a que somos submetidos a partir de uma visão ampla que envolve conhecimentos de diferentes áreas. Neste sentido, devemos empregar para a solução dos problemas que nos envolve diferentes competências relacionadas com nossa capacidade de expressão por meio da linguagem falada e escrita, pelo domínio das outras linguagens simbólicas, dos conceitos oriundos da Matemática, da Física e das outras áreas científicas, entre muitas outras. Diante desta realidade plural em sua essência, percebemos a necessidade de mostrar ao aluno que os temas abordados e aprendidos na escola possuem direta relação com as diferentes áreas de conhecimento, uma vez que os conceitos estão atrelados uns aos outros. Deste modo, o professor do Ciclo II precisa sempre que estiver ao seu alcance proporcionar atividades que levem o aluno a perceber esta relação, conforme asseveram as atuais orientações curriculares (PCN Matemática, 1998).

Assim, o professor ao elaborar seu planejamento pode e deve na medida do possível utilizar questões e abordagens que propiciem a interdisciplinaridade. Esta interdisciplinaridade, no âmbito da educação fornecida nos espaços escolares, pode ser entendida como a conexão estabelecida entre os conteúdos e temas de diferentes disciplinas que compõem a grade curricular da escola, fornecendo uma visão não compartimentada dos conhecimentos inerentes às diferentes áreas e abrindo espaço para que sejam percebidas algumas das possíveis relações entre elas.

Ao trabalharmos com a Webquest visamos desenvolver uma atividade que privilegiasse uma abordagem interdisciplinar, uma vez que este tipo de enfoque possibilita aos estudantes perceber o conhecimento não de uma maneira fragmentada, mas sim de forma a integrar diferentes áreas de conhecimento, sendo este tipo de abordagem defendido em diferentes documentos que expressam as atuais orientações curriculares (PCN, 1999, PCN +, 2002, Kawamura, 2003, Nunes, 2002). Naturalmente, a busca de um uso mais adequado das ferramentas típicas da área de informática e a utilização mais freqüente do espaço específico presente na escola foi outro elemento motivador deste trabalho.

Portanto, visando a abordagem interdisciplinar pretendida, foram selecionadas algumas disciplinas da grade curricular da escola, pois acreditamos que poderiam contribuir com conhecimentos relacionados ao tema central em estudo, facilitando assim a aprendizagem mais ampla dos estudantes e alargando os horizontes da disciplina de Matemática. As demais disciplinas selecionadas foram: Ciências, Língua Portuguesa, Educação Artística e Informática. Em cada uma destas áreas foram estabelecidos objetivos a serem alcançados, destacando-se: 
Português - os alunos foram orientados a pesquisar a história das pipas, buscado verificar onde e quando surgiu e quais são suas utilizações nos dias atuais, sendo que essa pesquisa realizada na Internet serviu de base para a preparação de livretos com a História das Pipas. Nesta fase do desenvolvimento do aluno procuramos fortalecer a escrita e a leitura, a gramática e a interpretação de texto, objetivos centrais trabalhados pela professora de Português durante as atividades. Devemos ressaltar que os alunos não fizeram apenas uma cópia dos textos encontrados, pois eles pesquisaram em vários sites e reelaboraram tudo o que obtiveram em um único texto sobre a história das pipas, sendo este texto trabalhado pela professora.

Geografia - na área de Geografia foram abordados os fenômenos físicos ventos, furacões e as pressões atmosféricas ideais para o vôo das pipas, bem como as atividades do homem que podem interferir no meio ambiente. Foi abordado que os chineses utilizaram as pipas e os ventos para locomoção, proporcionando desenvolvimento para a região. Discutiu-se com os alunos o fato da intervenção do homem na natureza poder estar relacionada com acidentes como o furacão Katrina, que devido a construção dos diques e a sua má conservação provocou grandes destruições, despertando o aluno para atitudes responsáveis, tema abordado principalmente durante os seminários por eles apresentados. O seminário foi a atividade final realizada na apresentação de Geografia no dia da Mostra da Escola Gabriela Mistral. Assim, buscamos atender dois dos objetivos estabelecidos para Geografia para o Ciclo II do Ensino Fundamental, segundo os PCN, ou seja: a) identificar e avaliar as ações dos homens em sociedade e suas conseqüências em diferentes espaços e tempos, de modo que construa referenciais que possibilitem uma participação positiva e reativa nas questões sócio-ambientais locais. b) conhecer o funcionamento da natureza em suas múltiplas relações, de modo que o aluno compreenda o papel das sociedades na construção do território, da paisagem e do lugar.

Educação Artística - procurou-se destacar que arte ou criação pode-se fazer ao montar uma pipa, envolvendo a escolha do papel e as cores empregadas. Para a realização das pipas a escolha das cores era fundamental e para isso foi esclarecido ao aluno sobre a classificação das cores, analisando-se as cores frias e quentes. Os alunos fizeram moldes das pipias em diferentes cores em pequena escala para ter idéia do resultado final e só depois puderam montar suas pipas.

Matemática - a contribuição desta área se deu por meio da Geometria, com a construção dos modelos de pipas a partir de formas geométricas. Cada pipa foi confeccionada tendo como base os moldes realizados com palitos de churrasco, copiando formas geométricas como o pentágono e o quadrado, sendo feitas construções com régua e compasso e ainda calculadas a área e o perímetro das pipas construídas.

Informática - nesta área básica relacionada com a Webquest buscamos orientar pesquisas, utilizando os aplicativos modernos capazes de ampliar o universo cultural dos alunos, 
preparando-os entre outros aspectos para o mundo do trabalho, que requer cada vez mais o domínio de conhecimentos da área de informática. Os aplicativos trabalhados com os alunos foram: PowerPoint, para a preparação dos seminários; Word para a apresentação da pesquisa apresentada ao professor; Paint, para simulação da pipa a ser construída e Internet, sendo abordado como funciona sua navegação e o uso das barras de informação.

Assim, as diferentes áreas de conhecimento escolhidas forneceram diferentes contribuições para o desenvolvimento de um trabalho conjunto e integrado que contou com a participação de diversos professores, enriquecendo a proposta.

\section{A Geometria e a exploração do pensamento geométrico}

$\mathrm{Na}$ abordagem aqui descrita, o pensamento geométrico foi explorado através da criação de situações capazes de levar o aluno a produzir e analisar transformações de ampliação e redução, paralelismo, perpendicularismo e ângulos, além de estabelecer as relações métricas, conforme prevêem algumas das orientações curriculares vigentes (PCN - Matemática, 1998, pág. 81 e 82$)$.

Neste contexto de trabalho, as atitudes propostas buscaram promover o respeito às individualidades, com a valorização do trabalho coletivo e a utilização dos recursos tecnológicos (computadores) como instrumentos que auxiliam na resolução de problemas (PCN - Matemática, 1998, pág. 75), o que pode ser atendido ao empregarmos o uso da Webquest, que se baseia especificamente na utilização das páginas da Web.

O uso do computador é de fundamental importância para o pleno desenvolvimento do aluno e a Escola não pode fugir da responsabilidade de inserir esta prática no contexto diário do aluno (PCN - Português, 1998, pág. 90). Descobrir os diferentes modos de se utilizar um computador, não só como lazer, mas também como ferramenta de trabalho é fundamental para a escola. Assim, nós professores não podemos deixar de propor e realizar atividades que levem ao conhecimento de tais práticas amparados em desculpas baseadas em uma eventual indisciplina do aluno, que deve ser contornada ou minimizada por meio de um contrato didático estabelecido previamente com os estudantes. Por outro lado, temos que considerar que o computador já faz parte da nossa vida e não podemos deixar nosso aluno distante destas atividades. 


\section{A Webquest como ferramenta de apoio à aprendizagem}

A metodologia Webquest pode ajudar o professor a modernizar os meios e recursos educacionais, pois fornece informações concretas para tornar possível e efetivo o uso da Internet. Esta é, portanto, uma clara maneira de praticar uma educação sintonizada com nosso tempo, onde os recursos computacionais encontram-se cada vez mais presentes no cotidiano dos individuos.

Esta prática garante o acesso a informações atualizadas, devendo-se tomar cuidados para que sejam utilizados apenas sites confiáveis, pois os conteúdos publicados na Internet, sobretudo os produzidos profissionalmente, tendem a refletir saberes e informações recentes.

As Webquest estão baseadas na convicção de que aprendemos mais e melhor com os outros do que sozinhos, de modo que as aprendizagens significativas são resultados de atos de cooperação, sendo o trabalho cooperativo defendido a tempos por Freinet $(1974,1985)$. Desse modo, procuramos apoiar nossa atividade no trabalho cooperativo, uma vez que acreditamos na maior potencialidade de haver produção e troca de saberes neste tipo de ambiente educacional, favorecendo o processo de aprendizagem.

O desenvolvimento de uma Webquest requer basicamente dois momentos distintos, um na sala de informática e outro na sala de aula ou outro local onde as atividades serão preparadas.

A interdisciplinaridade é contemplada e se insere na proposta das atividades, sendo o computador visto como uma ferramenta de trabalho, útil para que os alunos possam obter as informações necessárias. Desta forma, o trabalho do professor tem uma importância a mais, na medida em que o mesmo atua não como transmissor de conhecimento, mas como mediador no processo de ensino e aprendizagem. Surgem assim, condições para que se manifeste um novo professor, com propostas mais atraentes e capazes de contemplar um ensino que envolve elementos do antigo e do novo proceder.

Para que este professor mediador tenha sucesso em sua empreitada acreditamos que ele precisa estar em constante capacitação para poder utilizar esta metodologia e viabilizar a desejada interdisciplinaridade, aspectos que requerem do professor o domínio dos conteúdos que possam ser propostos com vistas a tornar a aprendizagem dinâmica e atual.

Podemos afirmar que o uso adequado dos computadores tende a proporcionar uma maior interação entre alunos, professores e o conteúdo, propiciando avanços para os processos de ensino e de aprendizagem, havendo autores que defendem o uso desses equipamentos sob diferentes enfoques (Fiolhais, 2003; Rosa, 1995; Valente, 1996, Veit, 2006). 


\section{Etapas de desenvolvimento do trabalho}

Neste momento procuraremos descrever as diferentes etapas que fizeram parte do desenvolvimento do trabalho proposto.

\subsection{Encontro com os professores}

Este momento acorreu por uma hora duas vezes por semana, onde cada professor pode conhecer o projeto antes dos alunos e adaptá-lo a sua forma de trabalhar, procurando entretanto garantir o foco na interdisciplinaridade. Cada professor procurou realizar previamente a atividade que faria com seus alunos, inclusive na sala de informática, buscando conhecer os programas e a Internet, aprendendo como se "navega" e como os alunos obteriam as respostas para as perguntas propostas.

Nos encontros programamos a construção de pipas pelos professores para que pudessem conhecer algumas das possíveis dificuldades apresentadas pelos alunos, sendo este fato de extrema importância para que pudessem colaborar na superação destas dificuldades.

\subsection{Apresentação do projeto aos alunos}

A apresentação do projeto foi feita pelo professor de Matemática em sala de aula, fornecendo esclarecimentos sobre o Projeto Pipas Geometria e Lazer e sobre todas as sua etapas, reforçando a necessidade de envolvimento dos alunos com todas as atividades e o que seria desenvolvido em cada disciplina. Foi esclarecido também que a nossa meta era montar uma Oficina de Pipas, onde um grupo determinado de alunos ajudasse os convidados (pais, irmãos, colegas, primos etc) a fazer a sua própria pipa, enquanto outro grupo de alunos estaria escalado para explicar o que faz com que a pipa voe e permaneça no céu.

Neste momento formamos as equipes de estudantes e distribuimos os temas a serem pesquisados por cada uma.

\section{3 - A pesquisa orientada}

Os alunos foram levados à sala de informática e lá conheceram detalhes complementares acerca do Projeto Pipas Geometria e Lazer, iniciando a pesquisa solicitada, uma vez que na medida em era montada a Webquest a mesma já poderia ser apresentada. Para as 6a séries planejamos o desenvolvimento de três aulas na sala de informática, pois o aluno teria que copiar os dados necessários da sua pesquisa, uma vez que o ambiente não dispõe de impressoras. $A$ Figura 1 ilustra um momento em que os estudantes estavam envolvidos com a realização da atividade de pesquisa na Sala de Informática. 


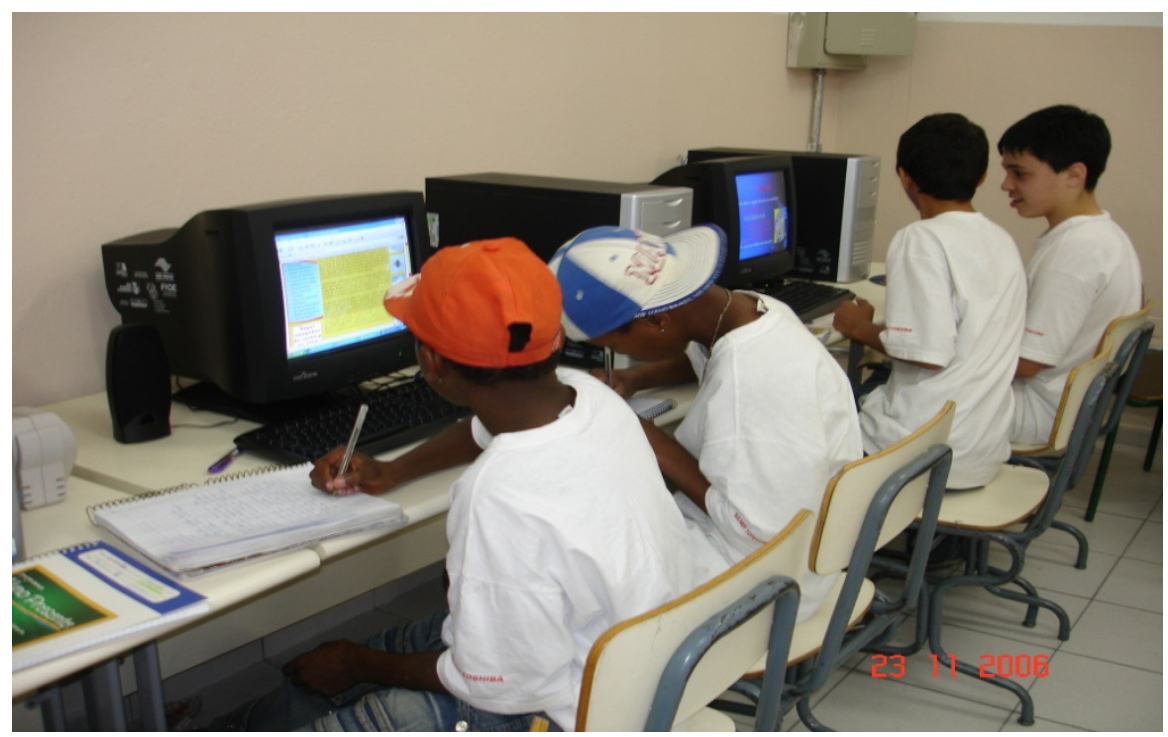

Fig. 1 - Alunos envolvidos com a pesquisa na Sala de Informática.

\section{4 - 0 trabalho em sala de aula}

Após a pesquisa orientada na Sala de Informática os alunos já conheciam as metas estabelecidas em cada disciplina e o que teriam de desenvolver. Durante as aulas de Matemática trabalhamos a Geometria que envolve uma pipa, os conceitos, as propriedades, as construções com régua e compasso, a aritmética da área e do perímetro. Para cada modelo de pipa escolhido foi feito seu estudo geométrico correspondente e registrado em cartazes que deram origem ao painel denominado "Construindo sua Pipa". A seguir registramos uma parte do painel elaborado.

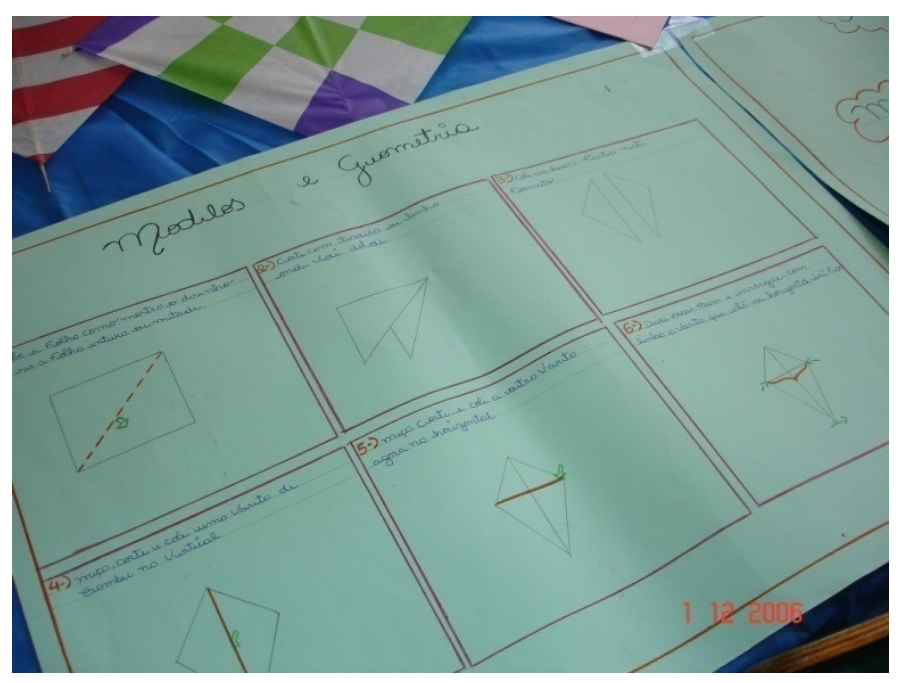

Fig 2 - Trabalho sobre Geometria. 


\section{5 - Os seminários apresentados pelos alunos}

Os seminários apresentados pelos grupos de alunos propiciaram aos mesmos expor os resultados de suas pesquisas e foram realizados em sala de aula visando corrigir eventuais enganos e deixar o aluno seguro do que fazer e como agir em relação às etapas seguintes. $O$ tema do seminário foi "Como as Pipas Voam", tendo sido pesquisado durante as aulas de informática no site www.pipas.com.br. Cabe destacar que a disciplina em que seria discutido e elaborado o seminário foi Geografia.

A Figura 3 ilustra a apresentação de um seminário por parte de um dos grupos.

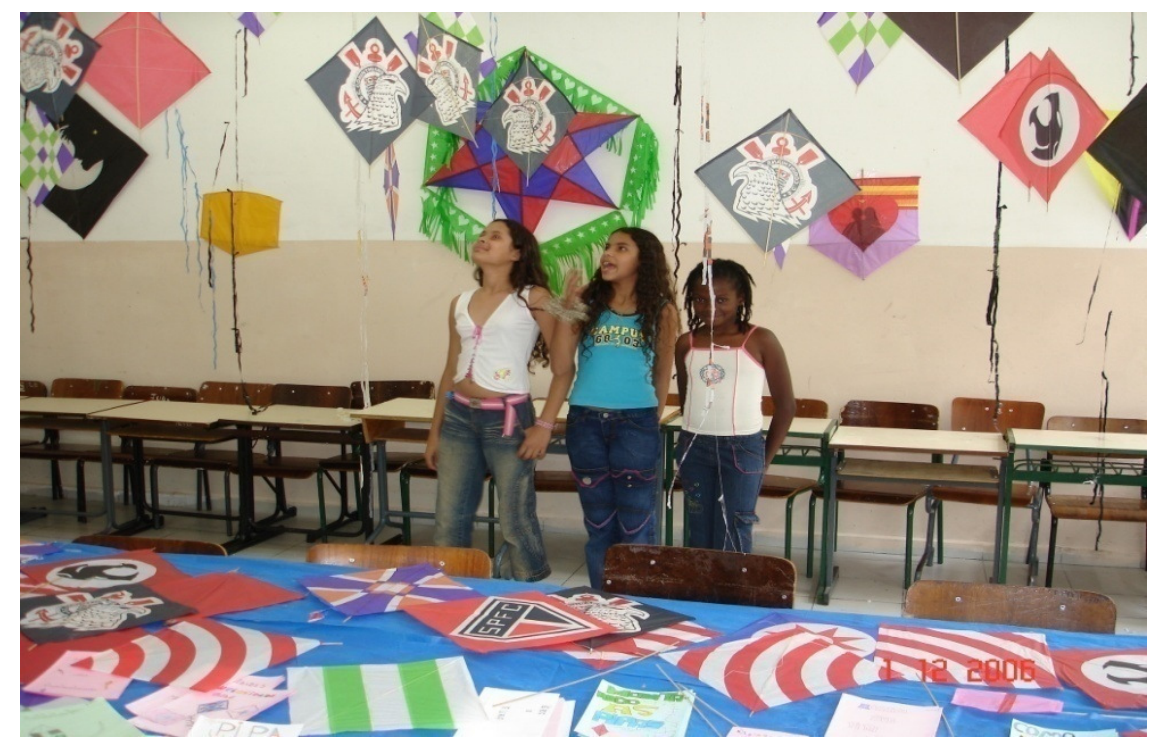

Fig. 3 - Um dos seminários apresentados pelos grupos de alunos.

\subsection{A confecção das pipas}

Durante as aulas de Matemática as pipas foram montadas, sendo abordados aspectos relacionados com a Geometria, além de terem sido bastante discutidas as propriedades dos quadriláteros, pois as pipas não poderiam ficar fora das especificações, caso contrario poderiam não levantar vôo.

Esta etapa do trabalho exigiu bastante atenção dos alunos, pois requeria o emprego de certo nível de habilidade manual.

A Figura 4 apresenta um grupo de alunos elaborando uma pipa. 


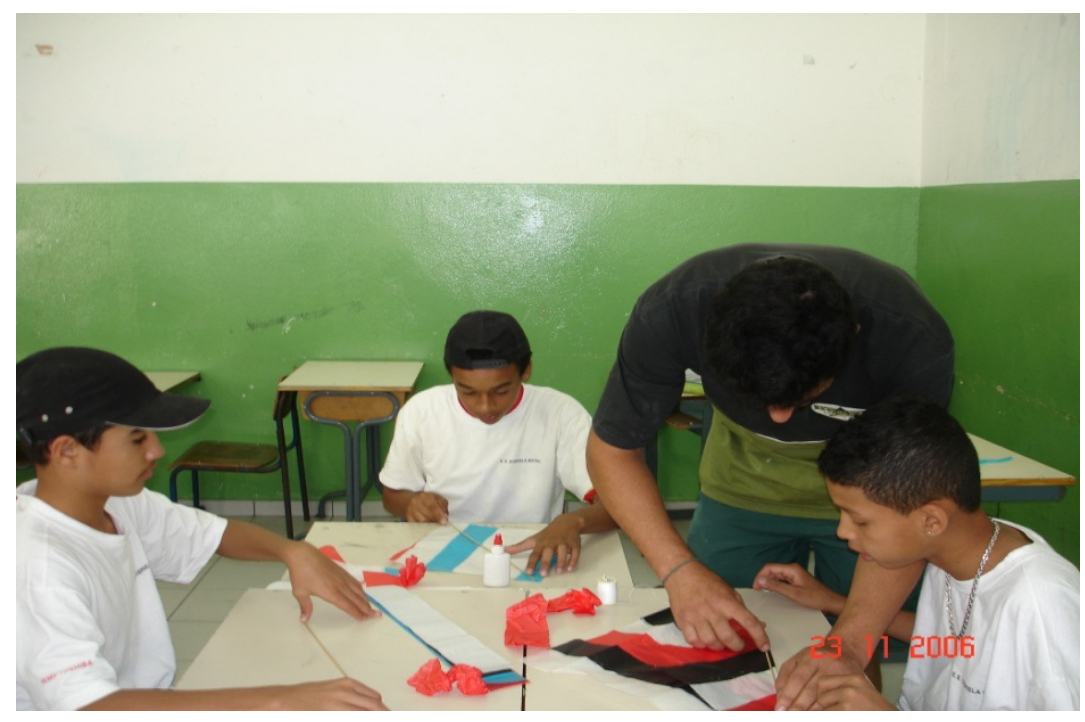

Fig. 4 - Grupo de alunos confeccionando uma das pipas.

\section{7 - A oficina de pipas}

A Oficina de Pipas foi programada para ser realizada no dia da Mostra Cultural da Escola Gabriela Mistral, ocasião em que equipes de alunos se revezaram para ensinar os convidados a fazer a sua própria pipa, que posteriormente foi presenteada ao convidado. A Mostra Cultural da Escola Gabriela Mistral é um evento que ocorre anualmente na escola com a finalidade de apresentar para a comunidade todas as atividades diferenciadas realizadas ao longo do ano. Trata-se de um projeto que ocorre nos meses de novembro ou dezembro e que apresenta um tema central sobre o qual todos os professores participam, contribuindo com abordagens relacionadas às suas áreas específicas de conhecimento. A figura 5 ilustra um dos espaços da escola utilizados para a realização da Mostra Cultural.

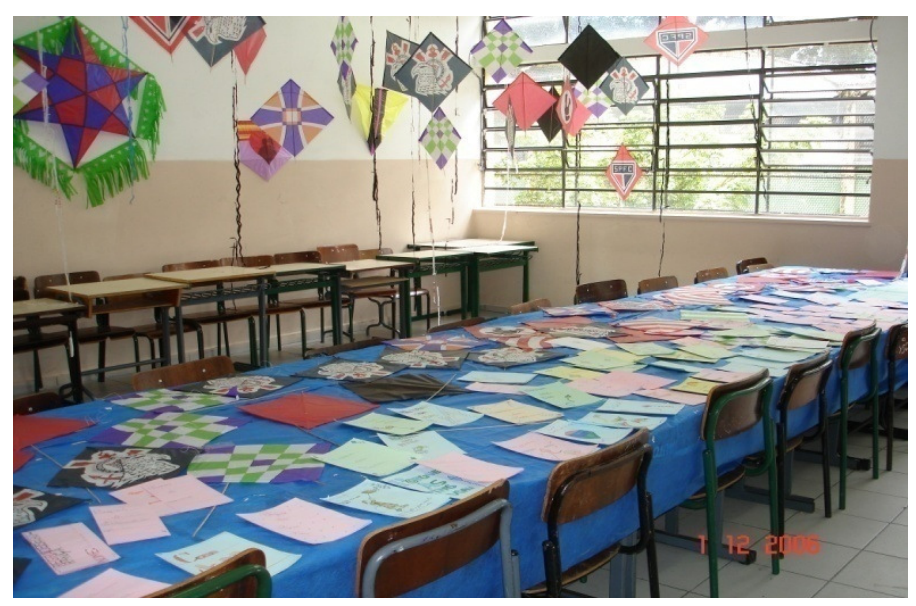

Fig. 5-A Oficina de Pipas exposta na escola. 


\section{Análise dos resultados obtidos}

O desenvolvimento do Projeto Pipas Geometria e Lazer na escola propiciou o alcance de diversos objetivos educacionais, relacionados com aspectos cognitivos, afetivos e comportamentais, conforme análise e discussão apresentada a seguir.

\subsection{Contribuições do projeto para a aprendizagem}

Como em geral a criança só aprende o que lhe faz sentido e, assim, incorpora esse novo conhecimento à sua estrutura cognitiva, ao preparar o Projeto Pipas Geometria e Lazer tivemos como parte de nossas intenções propiciar um novo sentido ao ato de empinar pipas, brincadeira esta que as crianças sentem grande prazer em praticar. $O$ fato de o aluno ter prazer em ir para a escola, pois estava envolvido com o desenvolvimento de um projeto capaz de despertar seu interesse pelo conhecimento, pela aprendizagem, estimulando-o a estudar, pesquisar e brincar com o que aprendeu é um ideal perseguido por todo professor.

Visando avaliar alguns aspectos relacionados com a aprendizagem dos estudantes realizamos uma análise estatística básica dos resultados de uma avaliação aplicada nas três turmas envolvidas, seis meses após as atividades do referido Projeto, com o objeto de verificar o que $o$ aluno assimilou com as atividades realizadas. A avaliação foi feita a partir de uma atividade simples e que envolveu os temas abordados no Projeto Pipas Geometria e Lazer, consistindo em propor aos alunos o reconhecimento das figuras geométricas utilizadas e solicitar que estabelecessem as propriedades dos quadriláteros.

Como resultado dessa avaliação, constatou-se que a média de acertos com os respectivos desvios padrões para as $6 \underline{a}$ s, 7 a $s$ e 8 a $s$ séries foram, respectivamente, 7,5 $\pm 1,2 ; 6,8 \pm 1,7$ e 7,1 \pm 0,7 . Estes resultados indicam que as três turmas apresentaram um rendimento semelhante e que o nível de heterogeneidade foi um pouco maior para a 7ạ série, o que pode ser justificado pelo fato de que nesta turma temos três casos de alunos em trabalho de inclusão social. Estes três alunos apresentam deficiência mental e em geral um baixo rendimento escolar, embora seja perceptível um progresso dentro de suas limitações. Apesar disso, podemos afirmar pelos resultados obtidos que o Projeto Pipas Geometria e Lazer foi capaz de contribuir para a aprendizagem dos estudantes, servindo de estímulo para que realizemos outras atividades interdisciplinares envolvendo temas matemáticos, uma vez que assim podemos tornar as aulas mais dinâmicas e despertar o interesse e a motivação dos alunos para a aprendizagem.

Para Gardner (apud Zacharias, 2006), é preciso diversificar as aulas e permitir que os alunos utilizem e desenvolvam todas as suas inteligências. Acreditamos que estes aspectos podem ser alcançados pelo professor ao utilizar a WebQuest como uma ferramenta de apoio, pois 
o aluno deverá ler, escrever, preparar seminários, elaborar desenhos, trabalhará o corpo com as corridas para empinar as pipas, utilizará suas capacidades manuais, praticará a cooperação com o amigo e socializará o conhecimento adquirido com os demais colegas de turma.

Com certeza o ato de empinar pipas não será mais o mesmo para os alunos que participaram do projeto proposto, uma vez que a sua percepção se modificou, podendo captar outros aspectos da realidade que antes se mostravam encobertos.

\subsection{0 trabalho colaborativo e as modificações nos relacionamentos}

Durante os trabalhos a Escola Gabriela Mistral se transformou em um ambiente propício à aprendizagem, não só entre os alunos, mas também entre os professores, pois o conhecimento trabalhado interdisciplinarmente entre alunos e professores foi socializado na medida em que todos ensinavam e todos aprendiam coisas novas. Descobrimos um novo aluno e um novo professor e mais uma vez a pedagogia de Freinet $(1974,2000)$ estava presente, resgatada pelo trabalho colaborativo no ambiente escolar, que facilitava a construção do conhecimento, a comunicação, o compartilhamento de saberes, além dos elementos de afetividade alcançados gerando uma nítida redução dos conflitos.

Nesta atividade podemos ver também que sem a adequada intervenção do professor o sucesso do educando não seria alcançado. Neste sentido, entendemos que o professor precisa estar em constante capacitação, que Ihe permite uma atuação profissional mais competente e com a qual adquire consequentemente reconhecimento e valor (Ponte, 1996).

\subsection{A relação professor-aluno}

Por meio das interações aprofundadas com os professores, os alunos não apenas reproduzem, mas ampliam seus conhecimentos, adquirindo autonomia para também utilizar outros aplicativos e recursos associados às tecnologias computacionais, como o editor de textos de apresentações e a biblioteca eletrônica. Este aspecto, a nosso ver, tornou o uso da tecnologia uma ferramenta de estudos e despertou o espírito investigativo dos estudantes. Assim, tornando a formação do aluno mais ampla e incentivando o trabalho coletivo, foi possível ao professor estimular a cooperação e o respeito às individualidades. Neste sentido, cabe salientar a importância das interações sociais como fator capaz de propiciar a aprendizagem, uma vez que, conforme afirma Vygotsky (2000), o homem se constrói em contato com o outro.

Portanto, as relações entre o professor e o aluno passam a ter um novo significado, na medida em que o professor assume um papel de orientador da aprendizagem, enquanto o aluno passa a aprender a aprender, incorporando a desejada autonomia de pensamento e ação, que é uma das principais metas da educação atualmente (Luz, 2007). 


\subsection{A relação professor-professor}

Uma vez que para o desenvolvimento da atividade optou-se por uma abordagem amplamente interdisciplinar, a colaboração entre diversos professores da escola envolvidos com diferentes disciplinas foi bastante expressiva. Neste sentido, ao enfrentarem algum tipo de problema bastava procurar por outro professor envolvido com o projeto e por meio de discussões buscar esclarecer as suas dúvidas.

Os encontros dos HTPC's serviram também para esclarecer uns aos outros as atividades a serem realizadas e as que seriam feitas no âmbito de cada disciplina. Podemos afirmar que os laços de amizade e de respeito mútuo foram ampliados em decorrência das intensas trocas de experiências e das constantes interações motivadas pelo desenvolvimento do projeto.

\subsection{A relação aluno-aluno}

Durante o desenvolvimento do projeto procuramos mostrar a existência de relações entre tudo ao nosso redor com as formas geométricas, sendo este aspecto do trabalho pertinente e bastante explorado. Os alunos que não perceberam o fato foram auxiliados pelos colegas, sendo esta interação capaz de favorecer a cooperação e a colaboração, de modo que a solidariedade foi uma marca constante na relação entre eles. Assim, uma das principais conquistas decorrentes da proposta de trabalho destaca-se justamente a intensificação da relação entre os estudantes, que assim puderam compartilhar conhecimentos e buscar auxiliar uns aos outros.

O trabalho cooperativo, nos moldes da concepção de Freinet $(1974,2000)$, tende a estimular o amadurecimento dos estudantes, fazendo crescer sua responsabilidade para com os indivíduos à sua volta, além de estimular a sua autonomia pessoal.

\subsection{A relação escola-família}

Finalmente, a Oficina de Pipas consistiu em um espaço aberto que recebeu a visita de muitas crianças da comunidade, além de alunos das escolas vizinhas convidados para o evento, e dos pais que também compareceram ao evento. Todos os participantes puderam levar uma pipa para casa, ou seja, aquela que conseguiu fazer com as orientações dos estudantes ou uma outra pipa que lhes foi dada de presente dentre aquelas que já estavam prontas.

Os alunos da ETI Gabriela Mistral, seguindo o programado, se esforçaram para ensinar a todos que estavam dispostos a aprender, além de apresentarem seminários explicando a história das pipas, sua origem e algumas curiosidades relacionadas a elas, momentos considerados bastante interessantes e ricos em trocas de experiências com os membros da comunidade na qual a escola encontra-se inserida. 
Entendemos que a participação dos membros da comunidade na vida escolar é um fator de grande relevância para que se crie um ambiente de maior integração, valorização, participação e identidade entre os mesmos e as pessoas e atividades que compõem o ambiente escolar, fazendo gerar um sentimento de pertencimento ao mundo educacional ali experimentado.

\section{Considerações finais}

A busca pela interdisciplinaridade é uma das tarefas que cabe a todo professor e, nesta busca, o professor de Matemática tem encontrado dificuldades para promover este tipo de abordagem. Assim, a realização da atividade centrada no desenvolvimento de uma Webquest e contando com o aporte de conhecimentos oriundos de diferentes disciplinas na Escola Estadual Gabriela Mistral proporcionou um enfoque fundamentalmente interdisciplinar à proposta de elaboração do Projeto Pipas Geometria e Lazer.

Os computadores já fazem parte da nossa vida e a Escola não deve furtar se da responsabilidade de levar nossos alunos a entrar em contato com esta tecnologia. Neste sentido, consideramos o computador como uma promissora ferramenta capaz de proporcionar ao aluno condições para construir o seu conhecimento. Podemos destacar que a efetiva aprendizagem por parte dos estudantes demanda o uso de diferentes recursos potencialmente significativos por parte dos docentes, conforme salienta Masini (1999, p. 13) ao asseverar que:

O problema, pois, da aprendizagem em sala de aula constituir-se-á da utilização de recursos que facilitem a passagem da estrutura de conceitos da disciplina para a estrutura cognitiva do aluno, tornando o material significativo.

Neste contexto, acreditamos que através da Webquest podemos atingir diversos objetivos, pois vimos que o professor de Matemática pode promover a interdisciplinaridade com um tema relacionado à Matemática, no caso a Geometria. Devemos, assim, enfrentar criteriosamente os desafios relacionados ao uso dos recursos computacionais de modo a serem empregados como ferramentas facilitadoras da aprendizagem, conforme salienta Valente em seu trabalho (1996).

Entendemos que utilizando adequadamente essa ferramenta instrucional é possível proporcionar a construção do conhecimento pelo aluno, facilitando com que o mesmo possa reestruturar e reorganizar seus conceitos, além de abrir caminho para que aprimore sua capacidade de análise, reflexão e a relação com os fenômenos do seu cotidiano (Nogueira, et al., 2000).

Com a Webquest Pipas Geometria e Lazer constatamos a participação de todo corpo docente e discente, além do envolvimento dos demais membros da equipe pedagógica. 
O trabalho permitiu perceber um aluno diferente, responsável, interessado, preocupado em realizar as tarefas propostas. Além disso, verificamos nos alunos um comportamento colaborativo em suas atitudes frente aos demais colegas de grupo e de classe, cooperando e socializando o conhecimento adquirido, além de manifestar o respeito às diferenças.

Igualmente importante foi o fato de observamos o aluno aprendendo e aprender, manifestando a aquisição de autonomia no processo de aprendizagem. Esta nova postura dos alunos foi possível graças ao seu intenso envolvimento com a prática pedagógico proposta neste trabalho, que incluiu a realização de pesquisas que auxiliaram o processo de aprender a aprender, favorecendo uma prática na qual o aluno tende a ser o construtor do próprio conhecimento (Demo, 2003). A proposta contribuiu ainda para que os alunos se afastem de posturas passivas para, contrariamente, serem mais participativos dentro de um processo e em um ambiente capaz de facilitar o diálogo e a discussão em sala de aula (Carvalho, 1998).

Assim, a dinâmica das aulas foi profundamente modificada pela metodologia empregada neste trabalho, que envolveu o desenvolvimento de uma Webquest e a orientação para que os alunos realizassem pesquisas. Neste sentido, caminhamos em direção ao que assevera Demo (2003), pois este defende que precisamos modificar a sala de aula para que sirva como local de trabalho conjunto, possibilitando ao aluno assumir uma postura ativa e capaz de interiorizar conhecimento por meio da realização de pesquisas, seminários e debates, ampliando assim as condições para que possa raciocinar e refletir sobre os aspectos analisados.

No que se refere ao uso de seminários, Veiga (1991) destaca que se trata de uma técnica de pesquisa que, em seu desenvolvimento, pode demandar a utilização da exposição oral, da discussão e do debate, tendo como finalidade propiciar a pesquisa e ensinar como deve ser feita esta pesquisa. Assim, a realização de seminários tem como objetivo oportunizar o uso de uma técnica capaz de socializar o conhecimento gerado pelos alunos. Portanto, quando bem conduzido, o seminário pode proporcionar aos alunos condições para se apropriarem de conhecimentos que os tornarão mais críticos e com maior autonomia intelectual. Este processo de aquisição do conhecimento decorre não por transmição do professor, mas sim por meio de uma investigação prévia conduzida pelo aluno. Nesse sentido, podemos destacar Veiga (1991, p. 110), ao afirmar que "o aluno é visto como sujeito de seu processo de aprendizado, portanto o seminário não é simplesmente uma técnica de absorção de conteúdos".

Naturalmente, a postura do professor deve contemplar uma ampla abertura ao diálogo, de modo que este passe a ser base de sustentação e interlocução do docente perante seus alunos, conforme salienta Luz (2007, pág. 2):

O estabelecimento de diálogo entre professor e aluno deve ocorrer em um clima de reciprocidade e respeito, pois há necessidade de um envolvimento profícuo entre professor e 
aluno em função do cumprimento de uma atividade pedagógica que deve ocorrer de forma intencional, sistemática e planejada. Desse modo, cabe ao professor provocar questões, induzir reflexões e delinear caminhos que devem ser percorridos pelo aluno em direção a uma efetiva aprendizagem.

Desse modo, os bons resultados observados tanto no que se refere aos aspectos cognitivos como comportamentais e afetivos nos permitem afirmar que importantes objetivos educacionais puderam ser alcançados pelo desenvolvimento do projeto, com destaque para a intensificação das relações entre os alunos e também entre estes e os professores. Esse ambiente capaz de propiciar trocas de conhecimentos, sentimentos e emoções entre os diferentes atores educacionais encontra-se na base dos argumentos defendidos por Veiga (1989) quando este se refere aos aspectos psicológico e afetivo relacionados à educação.

O alcance dos objetivos previstos no projeto implantado na Escola Estadual Gabriela Mistral pode também ser constatado por meio dos depoimentos da Coordenadora Pedagógica, Profa. Tânia e de alguns professores envolvidos no desenvolvimento da proposta:

"Esse projeto foi bastante significativo para os alunos. A maneira que foi desenvolvido, elaborado e executado fez com que os alunos pensassem de uma maneira lógica dentro de um contexto lúdico. As pesquisas feitas pelos alunos na sala de informática também foram muito interessantes, pois o tema é para eles demais atraente. Sob a orientação da professora Márcia os alunos aprenderam e entenderam os perigos dos fios quando se solta a pipa; e levaram o projeto muito a sério." (Profa. Tânia - Coordenadora Pedagógica)

"O Projeto de Pipas é muito interessante. Através das pipas podem ser trabalhados conceitos matemáticos e incentiva os alunos a estudarem. $\mathrm{O}$ aluno adquire conhecimento através do projeto no qual eles acham divertido. Por esse motivo eu considero o projeto importante". (Prof. Ramses - Sala de Informática)

"Eu gostei da metodologia que foi utilizada no Projeto Pipas, pois na medida em que os alunos iam descobrindo as formas geométricas e as maneiras de construir as pipas, o seu interesse em concluir o projeto foi se intensificando. Acredito que a utilização do projeto veio a ajudar a trabalhar tanto valores pedagógicos como valores éticos e morais". (Prof. Emerson - Sala de Informática)

Por fim, podemos afirmar que os resultados verificados apontam para os potenciais inerentes ao uso da Webquest em um enfoque interdisciplinar, envolvendo a área de Matemática e diversas outras áreas de conhecimento que fazem parte do ambiente escolar de Educação Básica (Língua Portuguesa, Geografia, Educação Artística e Informática), aproximando os estudantes das ferramentas computacionais, cuja utilização é defendida por diversos autores (Fiolhais, 2003; Rosa, 1995; Valente, 1996, Veit, 2006), e abrindo caminho para a implantação de 
estratégias capazes de contribuir para a inclusão digital e valorizar o uso das salas de informática presentes em inúmeras escolas da rede pública de ensino, mas que freqüentemente encontramse subutilizadas, muitas vezes por falta de iniciativas dos próprios professores que compõem o corpo docente dessas escolas.

\section{Referências bibliográficas}

BRASIL, MEC, Secretaria de Educação. Parâmetros Curriculares Nacionais para o Ensino Médio (PCNEM), Parte III - Ciências da Natureza, Matemática e suas tecnologias. Brasília: MEC, 1998. . Parâmetros Curriculares Nacionais para o Ensino Médio (PCNEM), Língua Portuguesa, Brasília: MEC, 1998.

BRASIL, MEC/SEMTEC. PCN+ Ensino Médio: Orientações complementares aos PCN. Brasília: MEC/SEMTEC, 2002.

CARVALHO, Anna M. P. et al. Ciências no ensino fundamental: o conhecimento físico. São Paulo, SP: Scipione, 1998.

DEMO, Pedro. Educar pela pesquisa. Coleção Educação contemporânea, 5a edição. Campinas, SP: Autores Associados, 2003.

FIOLHAIS, C., TRINDADE, J. Física no Computador: O Computador como uma Ferramenta no Ensino e na Aprendizagem das Ciências Físicas. Revista Brasileira do Ensino da Física, v. 25, n. 3, p. 259-272, setembro de 2003.

FREINET, Celéstin. A educação pelo trabalho. Lisboa, Presença, 1974.

FREINET, Celéstin. Pedagogia do Bom Senso, Martins Fontes, São Paulo, 6ạ edição, 2000.

KAWAMURA, M. R. D.; Hosoume, Y. A contribuição da Física para um novo Ensino Médio. Física na Escola, v. 4, n. 2, 22-27, 2003.

LABURÚ, C. E., Arruda, S. M., Nardi, R. Pluralismo Metodológico no Ensino de Ciências. Revista Ciência \& Educação, v. 9, n. 2, p. 247-260, dezembro de 2003.

LUZ, Sérgio Luiz Correa da; Araújo, Mauro Sérgio Teixeira de; Maciel, Maria Delourdes. Resgatando o prazer de aprender a aprender: a pesquisa como veículo de aprendizagem. In: XVII Simpósio Nacional de Ensino de Física. São Luis. Anais... São Luis, 2007.

MASINI, E. F. S. Aprendizagem totalizante. Editora Mackenzie, São Paulo - SP, 1999.

NOGUEIRA, J. S. et al. Utilização do Computador como Instrumento de Ensino: Uma Perspectiva de Aprendizagem Significativa. Revista Brasileira de Ensino de Física, vol. 22, n. 4, p. 517-522, dezembro de 2000. 
NUNES, C. Ensino Médio - Diretrizes Curriculares Nacionais. Ed. DP \& A. Rio de Janeiro, 2002. PONTE, João Pedro. As Novas Tecnologias de Informática, Lisboa, Editora Texto - 1996.

ROSA, P. R. S. O Uso de Computadores no Ensino de Física. Parte I: Potencialidades e Uso Real. Revista Brasileira do Ensino da Física, v. 17, n. 2, p. 182-195, junho de 1995.

VALENTE, Armando. Informática na educação: conformar ou transformar a escola. Florianópolis, SC: CED/UFSC, 1996.

VEIGA, Ilma. Passos Alencastro. A prática pedagógica do professor de didática. Campinas, SP: Papírus, 1989.

VEIGA, Ilma. Passos Alencastro. Coleção magistério e trabalho pedagógico. Campinas, SP: Papírus, 1991, p. $103-113$.

VEIT, E. A., Pires, M. A. Tecnologias da Informação e Comunicação para Ampliar e Motivar o Aprendizado de Física no Ensino Médio. Revista Brasileira de Ensino de Física, vol. 28, n. 2, p.241248, junho de 2006.

VIGOTSKY, Lev S. A formação da mente. São Paulo, SP: Martins Fontes, 1984.

VIGOTSKY, Lev S. Pensamento e Linguagem, São Paulo, Martins Fontes, 2000.

ZACHARIAS, Vera Lúcia Câmara F., Gardner e a Inteligência, Disponível em:

http:/www.centrorefeducacional.com.br. /gardner.html. Acesso em: 07/12/2006.

Márcia Cristina dos Santos Ribacionka - Professora de Educação Básica na Escola Estadual Gabriela Mistral - São Paulo - SP. mcsriba@hotmail.com

Mauro Sérgio Teixeira de Araújo - Professor Titular na Universidade Cruzeiro do Sul - São Paulo SP.mstaraujo@uol.com.br

Rômulo Pereira Nascimento - Professor Titular na Universidade Cruzeiro do Sul. São Paulo - SP romulo.nascimento@unicsul.br 